\title{
Translation and validation of Portuguese of a questionnaire for evaluation of psychosomatic symptoms in adults with atopic dermatitis
}

\author{
Manuela Boleira ${ }^{1,2}$ \\ Gabriela Dias ${ }^{3}$
}

Omar Lupi ${ }^{1,2}$

Amanda Jaccobson Seba ${ }^{1}$

Gisele Vianna Pires ${ }^{1}$

Daniel Boleira Sieiro Guimarães ${ }^{4}$

DOI: http://dx.doi.org/10.1590/abd1806-4841.20142707

\begin{abstract}
BACKGROUND: atopic dermatitis is directly related to psychological stress, reduced quality of life and psychosomatic symptoms. The Psychosomatic Scale for Atopic Dermatitis is the only questionnaire developed specifically for assessment of psychosomatization in atopic dermatitis.

OвJестіVES: the objective of this study was to cross-culturally adapt and validate a Brazilian-Portuguese version of the Psychosomatic Scale for Atopic Dermatitis.

METHODS: adaptation consisted of independent translation and backtranslation by three bilingual translators, followed by a pre-test. The Psychosomatic Scale for Atopic Dermatitis and the Dermatology Life Quality Index were self-administered to 47 patients with atopic dermatitis. Disease severity was evaluated using the Eczema Area and Severity Index. Factor analysis was used to identify the dimensions of the Brazilian Portuguese version of the Psychosomatic Scale for Atopic Dermatitis. Internal consistency and convergence validity were also analyzed. Reproducibility was assessed using the Kappa coefficient.

RESULTS: factor analysis revealed a two-dimensional structure: stress/laziness/insecurity (I) and maladjustment/social relationships (II), explaining $54.4 \%$ of total variance. All dimensions revealed excellent internal consistency. External construct validity was confirmed by positive correlations between the Psychosomatic Scale for Atopic Dermatitis and the Dermatology Life Quality Index. Test-retest reliability was excellent, with $k>0.7$ for all questions.

Conclusions: the Brazilian Portuguese version of the Psychosomatic Scale for Atopic Dermatitis demonstrated acceptable psychometric properties and can be used for the evaluation of psychosomatic symptoms in patients with atopic dermatitis and as a tool in clinical and epidemiological research.
\end{abstract}

Keywords: Cost of illness; Dermatitis, atopic; Questionnaires; Stress, physiological; Stress, psychological; Validation studies

\section{INTRODUCTION}

Atopic dermatitis (AD) is a chronic inflammatory syndrome, characterized by recurrent episodes of eczema combined with itching. ${ }^{1}$ It affects around $20 \%$ of children and $1-3 \%$ of adults and occurrence is more common in women. ${ }^{2,3}$ The estimated prevalence among adults over 20 years of age is $2 \%$, while among adults over 40 it is $0.2 \%{ }^{4}$ Around $45 \%$ of all cases have onset within the first 6 months of life, and $70 \%$ of these children will enjoy spontaneous remission before adolescence. ${ }^{5}$ The disease can also emerge in adulthood (adult-onset atopic dermatitis). ${ }^{6}$ In addition to genetic heredity ( $80 \%$ agreement in monozygotic twins and $20 \%$ in heterozygotes), other factors, such as stress, can also affect its pathogenesis. ${ }^{7}$
Patients with atopic dermatitis suffer the greatest impairment of quality of life among skin diseases. ${ }^{8}$ Psychological stress can play an important role in the emergence of atopic diseases and is also an aggravating factor in $46-67 \%$ of adults patients with more serious forms of AD. ${ }^{9}$ Many atopic patients have some type of psychological or psychiatric disorder, such as anxiety, depression or neuroticism. ${ }^{8}$ Psychological problems and secondary social problems can emerge in response to clinical progression of $\mathrm{AD} .^{10}$

Psychosomatic assessment is essential for clinical management of patients with $\mathrm{AD}(8)$, but to date no questionnaire for this purpose exists in Portuguese. Instruments are available to assess quality of life that measure several different dimensions, including the

Approved by the Advisory Board and accepted for publication on 06.09.2013

Study conducted at Ambulatório do Serviço de Imunologia do Hospital Universitário Clementino Fraga Filho - Universidade Federal do Rio de Janeiro (HUCFF-UFRJ) - Rio de Janeiro (RJ), Brazil.

Financial Support: None

Conflict of Interest: None

Universidade Federal do Rio de Janeiro (UFRJ) - Rio de Janeiro (RJ), Brazil.

Policlínica Geral do Rio de Janeiro (PGRJ) - Rio de Janeiro (RJ), Brazil

Universidade do Estado do Rio de Janeiro (UERJ) - Rio de Janeiro (RJ), Brazil.

Universidade de Sherbrooke - Sherbrooke, Canadá. 
psychosomatic. ${ }^{11}$ The psychosomatic scale for atopic dermatitis (PSS-AD) questionnaire was developed specifically for this purpose. ${ }^{10}$ It was created in Japanese and has excellent psychometric properties. There is no questionnaire in Portuguese for studying the psychosomatic characteristics of atopic dermatitis. The objective of this study was to produce a Brazilian Portuguese version of the PSS-AD by means of crosscultural adaptation.

\section{MATERIALS AND METHODS}

Data were collected from September 2011 to November 2012 at an atopic dermatitis clinic run by the Hospital Clementino Fraga Filho. All participants were at least 18 years old and had atopic dermatitis diagnosed according to the Hannifin and Rajka criteria. ${ }^{12}$ The study was approved by the Hospital's Ethics Committee and all participants were given a written consent form. The target sample size was 44 patients, calculated on the basis of the variability of responses given by a sub-group of 10 patients assessed in a pretest. Simple randomized sampling was used for a finite population of $n=62$ patients registered at the atopic dermatitis clinic. A sample size was calculated for each item on the scale, and the respective standard deviation used, with a maximum acceptable error of $5 \%$ and a significance level of 0.05 . The sample size suggested was the mean of these sample sizes. All patients were invited to return 2 weeks after the first visit to test the questionnaire's reproducibility.

The PSS-AD contains 12 questions and the original version is divided into three dimensions: exacerbation (four items), disturbances (five items) and ineffective control (three items). The item responses relate to the intensity of symptoms during the preceding month, on a scale from 0 to 5 . The higher the score the worse the psychosomatic involvement. ${ }^{10}$ Semantic equivalence was tested following guidelines proposed by Herdman. ${ }^{13}$ The psychometric properties of the Brazilian version were investigated to test for validity, internal consistency and reliability.

Three bilingual translators conducted translations and backtranslations of the questionnaire independently. Two Brazilians translated the Japanese source text into Portuguese. These translations were revised by the research team to improve understandability of items and then combined into a single consensus version. A Japanese translator then backtranslated the consensus version into Japanese. The backtranslation was compared to the original source text, in order to detect any language errors, but the objective was to produce a version that was culturally similar, rather than a literal translation. A second consensus version was then developed.

A physician fluent in both languages assessed the integrity of the translation, identifying potentially problematic items. The second consensus version was tested with 10 atopic dermatitis patients in order to confirm that the translation was acceptable and understandable, using simple and appropriate language. Further modifications were made to arrive at the final version of the questionnaire in Brazilian Portuguese.

Patients were administered the Brazilian Portuguese version of the PSS-AD and the Dermatology Quality of Life Index (DLQI) ${ }^{14}$ during their routine medical consultations. The DLQI is an instrument for assessing quality of life in any type of dermatological disease and is designed for use in clinical practice. Higher scores indicate lower quality of life. A Portuguese version exists that has been validated for use in Brazil. . $^{1516}$

Disease severity was measured using the Eczema Area and Severity Index (EASI), in order to monitor patients' clinical stability. ${ }^{17}$ All patients were requested to return 2 weeks after the first consultation, when the PSS-AD and EASI were administered once more.

The percentages of patients scoring the lowest and highest scores in each PSS-ADD domain were measured to test for floor and ceiling effects respectively and the proportion of unanswered questions was calculated. Floor or ceiling effects greater than $15 \%$ were considered high. ${ }^{18}$

Tests of validity assess an instrument's capacity to measure characteristics of the population for which it was designed..$^{19}$ For this study, the internal and external construct validities of the Portuguese version of the PSS-AD were investigated. Exploratory factor analysis (EFA) was used for internal construct validation, which consists of assessing the dimensional structure of the instrument and the adequacy of its items. ${ }^{20}$ Considering that the PSS-AD is a recently developed questionnaire, EFA determines whether all of the variables studied (the questionnaire items) could be explained by a smaller number of factors. A data matrix was constructed using the 12 questions and the responses from the 47 patients enrolled on this phase of the study. The data matrix was used to produce a covariance matrix and then principal component analysis was conducted, using the linear combinations of the original variables to generate their principal n-components, which were obtained in descending order of maximum variance. The criterion for selecting principal components was an eigenvalue greater than or equal to 1 . The eigenvalues indicate the importance of each factor in explaining the variance of the data. After the factors had been extracted, the dataset was subjected to Varimax rotation and finally, the items (questions) were related to their cor- 
responding factors if they had a factor loading $\geq 0.4$. External construct validity was estimated by calculating Pearson correlation coefficients for the relationship between the Portuguese PSS-AD and the items on the DLQI. Correlations of $<0.30 ; 0.30-0.60$ and $>$ 0.60 were defined as weak, moderate and strong, respectively. ${ }^{21}$

Internal consistency reflects the homogeneity of measurements within the study. Cronbach's alpha was calculated to assess the internal consistency of data and results $>0.7$ were considered optimum. ${ }^{21}$ Reproducibility refers to the degree to which an instrument produces stable results over a short period of time, assuming that there have been no clinical changes in the meantime. Clinical stability was controlled by administering the EASI after a 2-week interval and then the Kappa (k) statistic was calculated for 19 patients whose EASI scores were stable; and k> 0.61 was considered excellent. ${ }^{22}$

\section{RESULTS}

A total of 47 individuals with a mean age of 34 years took part in the study, $63.8 \%$ of whom were women. Nineteen $(40.4 \%)$ patients returned for the second consultation. A total of $53.1 \%$ of the patients were on continuous treatment with antihistamines. The majority of then reported that their symptoms had had onset in childhood $(53.2 \%)$ and $57.4 \%$ had personal histories of asthma or rhinitis (Table 1).

TABLE 1: Sociodemographic and clinical characteristics of the study population for the validation phase

\begin{tabular}{|c|c|}
\hline Variable & $n=47(n / \%)$ \\
\hline Women & $30(63.8)$ \\
\hline Men & $17(36.2)$ \\
\hline Mean age & 34 years $( \pm 13.41)$ \\
\hline \multicolumn{2}{|l|}{ Allergic respiratory diseases } \\
\hline Asthma & 14(29.7) \\
\hline Allergic rhinitis & $24(51)$ \\
\hline \multicolumn{2}{|l|}{ Continuous medication } \\
\hline Antihistamine & $25(53.1)$ \\
\hline Oral prednisone & $8(17)$ \\
\hline Oral immunosuppressor & $10(21.2)$ \\
\hline \multicolumn{2}{|l|}{ Onset of skin symptoms } \\
\hline Childhood (before 11 years of age) & $25(53.2)$ \\
\hline Adolescence (12 to 17$)$ & $6(12.8)$ \\
\hline Adulthood (after 18) & $16(34)$ \\
\hline
\end{tabular}

Exploratory factor analysis revealed a twodimensional structure that explained $54.4 \%$ of total variance. Items were grouped into factors on the basis of factor loadings $>0.4$. Only item 2 was allocated to dimension I, with a factor loading of 0.39 (Table 2). Domains I and II exhibited excellent consistency (Table 3). Domains I and II were named, respectively, maladjustment/relationships and stress/laziness/insecurity; on the basis of the content of their items. Cronbach's alpha coefficient was calculated for the two domains as a measure of internal consistency (Table 4).

Dimension II scored highest, with a mean score of 64.55 (0-100). The questions with the highest mean scores were item 4 , followed by items 1 and 9 . Item 8 had the lowest score, followed by items 7 and 2 (Table 5).

Mean DLQI score was $12.8 \pm 7.32$ (variation of 1-28). The correlation between mean total scores on the DLQI and the PSS-AD was statistically significant $(r=0.78, p<0.00001)$. Dimension II of the PSS-AD (maladjustment/relationships) was correlated with all items on the DLQI (Table 6). Dimension I (stress/laziness/insecurity) had a moderate correlation with the majority of the items on the DLQI, particularly with items 1 (itching) $(\mathrm{r}=0.42), 6$ (sports) $(\mathrm{r}=0.47)$ and 10 (treatment) $(\mathrm{r}=0.44)(\mathrm{p}<0.05)$.

Mean EASI score was 28.84 (2.8-68.4). It did not have statistically significant correlations with the PSSAD total score or dimension scores $(p>0.05)$. The Kappa (k) coefficients calculated for each PSS-AD item were considered optimum and are shown in table 7.

\section{DISCUSSION}

The psychological impact of atopic dermatitis is well-established, interfering with patients' ability to perform their daily activities and causing physical discomfort. ${ }^{23}$ Harth suggests that clinical management should be enriched by the use of instruments to assess quality of life in dermatology or scales specifically for psychosomatic assessment. $^{8}$

Atopic dermatitis has a negative impact on patients' interpersonal relations. A recent study showed that $57.5 \%$ of patients with $\mathrm{AD}$ reported reduced sexual drive. ${ }^{24}$ One study assessed 1,972 adult patients, a majority of whom had $\mathrm{AD}$, and observed that eczema primarily affects social activities, leisure, work and personal relationships. ${ }^{25}$ Another group studied 112 different types of skin diseases, including

TABLE 2: Determination of the dimensional structure of the Brazilian Portuguese version of the PSS-AD

\begin{tabular}{|c|c|c|c|c|c|}
\hline \multirow[b]{2}{*}{$\begin{array}{c}\text { Factors } \\
\text { I } \\
\text { II }\end{array}$} & \multirow{2}{*}{$\begin{array}{l}\text { Eigenvalues } \\
\text { Total } \\
5.13 \\
1.39\end{array}$} & \multicolumn{2}{|c|}{$\begin{array}{l}\text { Extraction of the Sum of } \\
\text { Squared Factor Loadings }\end{array}$} & \multicolumn{2}{|c|}{$\begin{array}{l}\text { Rotation of the Sum of Squared } \\
\text { Factor Loadings }\end{array}$} \\
\hline & & $\begin{array}{l}\% \text { of Variance } \\
42.76 \% \\
11.64 \%\end{array}$ & $\begin{array}{l}\text { Accumulated \% } \\
42.76 \% \\
54.4 \%\end{array}$ & $\begin{array}{l}\% \text { of Variance } \\
35.68 \% \\
18.72 \%\end{array}$ & $\begin{array}{l}\text { Accumulated \% } \\
35.68 \% \\
54.4 \%\end{array}$ \\
\hline
\end{tabular}


TABLE 3: Distribution of eigenvalues for Brazilian Portuguese PSS-AD items

\begin{tabular}{lll}
\hline Item & Factor I & Factor II \\
\hline 01. The skin allergy worsens with stress. & 0.8248 & 0.2247 \\
02. The allergy makes me feel too lazy to do anything. & 0.3918 & 0.0280 \\
03. I don't understand why I'm not getting better despite the treatment. & -0.1070 & 0.7975 \\
04. The itching increases when I get nervous. & 0.6717 & 0.0436 \\
05. I feel that I don't have good relationships with other people because of the allergy. & 0.3623 & 0.1221 \\
06. I don't understand why the skin allergy gets worse all the time. & 0.2377 & 0.5418 \\
07. I scratch my skin because I feel insecure and nervous. & 0.1902 & 0.6996 \\
08. I don't understand why I'm the only one who suffers this disease. & 0.6429 & 0.3977 \\
09. The itching appears when I'm angry, nervous or sad. & 0.0899 & 0.4631 \\
10. I feel that I won't be able to do anything until the allergy gets better. & 0.3634 \\
11. I did everything the doctor told me to, but I can't see any results. & 0.7732 \\
12. I'm worried by other people looking at me, because of my disease. & 0.6320 \\
\hline
\end{tabular}

TABLE 4: Distribution of scores and internal consistency of PSS-AD

\begin{tabular}{lll}
\hline Item & Mean score (0-100) & Cronbach's $\boldsymbol{\alpha}$ \\
\hline SSAD & $47.71( \pm 21.06)$ & 0.88 \\
D1(items) & $64.55( \pm 19.1)$ & 0.74 \\
D2 & $39.3( \pm 26.05)$ & 0.89 \\
\hline
\end{tabular}

TABLE 5: Distribution of scores by item

\begin{tabular}{lc}
\hline Items & Mean score (0-5) \\
\hline 01. The skin allergy worsens with stress. & $3.80( \pm 1.03)$ \\
02. The allergy makes me feel too lazy to do anything. & $1.61( \pm 1.58)$ \\
03. I don't understand why I'm not getting better despite the treatment. & $2.08( \pm 1.74)$ \\
04. The itching increases when I get nervous. & $4.08( \pm 1.05)$ \\
05. I feel that I don't have good relationships with other people because of the allergy. & $1.80( \pm 1.63)$ \\
06. I don't understand why the skin allergy gets worse all the time. & $2.12( \pm 1.87)$ \\
07. I scratch my skin because I feel insecure and nervous. & $1.51( \pm 1.48)$ \\
08. I don't understand why I'm the only one who suffers this disease. & $1.23( \pm 1.65)$ \\
09. The itching appears when I'm angry, nervous or sad. & $3.40( \pm 1.48)$ \\
10. I feel that I won't be able to do anything until the allergy gets better. & $1.82( \pm 1.74)$ \\
11. I did everything the doctor told me to, but I can't see any results. & $1.97( \pm 1.83)$ \\
12. I'm worried by other people looking at me, because of my disease. & $3.14( \pm 1.57)$ \\
\hline
\end{tabular}

TABLE 6: Pearson's correlation coefficients for PSS-AD dimensions and DLQI items

\begin{tabular}{|c|c|c|}
\hline & PSS-AD Domains & \\
\hline DLQI items & D1 & D2 \\
\hline Itching & $0.4265(p=0.0028)$ & $0.5779(\mathrm{p}<0.00001)$ \\
\hline Embarrassment & $0.3970(\mathrm{p}=0.0057)$ & $0.6488(\mathrm{p}<0.00001)$ \\
\hline Activities at home & $0.2633(\mathrm{p}=0.0738)$ & $0.5554(\mathrm{p}=0.0001)$ \\
\hline Clothing & $0.3382(p=0.0201)$ & $0.6200(\mathrm{p}<0.00001)$ \\
\hline Social life & $0.3621(\mathrm{p}=0.0124)$ & $0.7072(\mathrm{p}<0.00001)$ \\
\hline Sport & $0.4711(p=0.0008)$ & $0.7548(\mathrm{p}<0.00001)$ \\
\hline Work/studies & $0.2910(p=0.0472)$ & $0.6281(\mathrm{p}<0.00001)$ \\
\hline Relationships & $0.2920(p=0.0046)$ & $0.6749(\mathrm{p}<0.00001)$ \\
\hline Sexual activity & $0.4091(p=0.0043)$ & $0.6822(\mathrm{p}<0.00001)$ \\
\hline Treatment & $0.4473(\mathrm{p}=0.0016)$ & $0.6595(\mathrm{p}<0.00001)$ \\
\hline
\end{tabular}

Figures in bold are different from 0 to an alpha significance level of 0.05 
TABLE 7: Kappa coefficients for PSS-AD items

\begin{tabular}{ll}
\hline PSS-AD item & Kappa Coefficient \\
\hline Item 1 & 0.84 \\
Item 2 & 0.83 \\
Item 3 & 0.83 \\
Item 4 & 0.82 \\
Item 5 & 0.77 \\
Item 6 & 0.74 \\
Item 7 & 0.77 \\
Item 8 & 0.87 \\
Item 9 & 0.77 \\
Item 10 & 0.76 \\
Item 11 & 0.75 \\
Item 12 & 0.79 \\
\hline
\end{tabular}

$\mathrm{AD}$, administering the "Dermatology Life Quality Index" (DLQI), and found that patients with atopic dermatitis had the highest DLQI scores. ${ }^{26}$ Another research team observed that $\mathrm{AD}$ has a major impact on health-related quality of life and that social and psychological wellbeing are the most affected elements. ${ }^{27}$

Few studies conducted in Brazil have been published on the impact of atopic dermatitis and its psychosomatic features in adult patients. Prior to this study, there were no instruments designed to measure these, which was the motivation for cross-culturally adapting the PSS-AD. Studies that have been published to date have employed quality of life instruments to investigate this aspect of the disease or studied samples of children. ${ }^{28-31}$

The cultural adaptation process was followed by the author of the original Japanese questionnaire. The Brazilian Portuguese version of the PSS-AD proved to be a valid and reliable instrument that can be considered semantically equivalent to the original instrument. Conceptual and item equivalence showed that the concepts proposed are applicable to our setting. Patients did not leave items blank and both floor and ceiling effects were less than 15 . Factor analysis of the Brazilian Portuguese version of the PSS-AD revealed a two-dimensional solution, whereas the Japanese version has three domains, although its author discloses that he accepted an eigenvalue of less than 1 (0.93) for one of these domains because of a question of interpretation (10). Factor analysis of the Portuguese version resulted in eigenvalues of 5.13 and 1.39 , in addition to explaining $54.4 \%$ of the total variance in the replies given to the questionnaire. The two-dimensional solution found in this study has both validity and excellent internal consistency, with Cronbach's $\alpha$ greater than 0.7 for all dimensions and an overall coefficient of 0.88 .

Dimension I (stress/laziness/insecurity) included items that are linked with the extent to which patients relate their disease to states of nervousness, insecurity, laziness and stress. With regard to this dimension, it is necessary to comment on Item 2, which had a factor loading $<0.4$ for both dimensions. Since its factor loading for Dimension I was higher, it was allocated to that domain. Item 2 is related to a lack of the desire or drive to do things because of the disease. The factor loading with low values for both dimensions may reveal inconsistencies with this item. The team wonders whether the word "laziness" may not have a pejorative character in the Brazilian culture, associated with people who refuse to work for no real reason. This term was accepted during the translation process because it is colloquial and easily understood, bringing the questionnaire closer to the target population culturally. However, after further discussions, facilitated by the translators, in view of the statistical findings the authors suggest using the following question instead: "The skin allergy makes it harder for me to do my tasks".

The total mean PSS-AD score was 28.63 (0-60), which is similar to the results of the article presenting the original questionnaire at $31.64(0-60)(10)$. This finding shows that our patients suffer significant psychosomatic involvement. Dimension I had a higher mean score than Domain II. This signifies that items 1 , 2, 4 and 9 make a greater contribution to the total score than Domain II, showing the weight of items related to stress, laziness, nervousness and insecurity.

The Dimension I items are pertinent because states of anxiety can be expressed as nervousness, just as depression can be expressed by a lack of vitality and by insecurity. The tendency for stressful situations to exacerbate this disease has already been very well-documented. Studies show that stress is an aggravating factor in $46-67 \%$ of adult patients. ${ }^{9}$ Dimension II (maladjustment/relationships) of the PSS-AD contains five items related to the phenomenon of patients not understanding their disease.

The item with the highest mean score was question 4, "The itching increases when I am nervous", followed by question 1, "The skin allergy worsens with stress". This finding confirms the major impact that atopic dermatitis has on patients' mental health. Psychological or psychiatric conditions such as anxiety disorders, depression and neuroticism have been seen in patients with atopic dermatitis (8). Researchers have demonstrated that children and adults with $A D$ have higher anxiety levels than non-sufferers. ${ }^{32}$ Gupta and Gupta observe that in $70 \%$ of cases stress-related events can make AD more acute. ${ }^{33}$

Many studies of psychosomatization have been conducted without using a specific instrument, instead relying on scales for assessment of anxiety and depression to identify patients with atopic dermatitis who have significant psychosomatic symptoms. ${ }^{32,34}$ During the methodology planning stage of this research, the issue of what might be the best way of 
assessing psychosomatic involvement of patients was discussed, since this would be the first questionnaire on psychosomatic symptoms in Brazilian Portuguese. Depression and anxiety are relevant psychiatric comorbidities in dermatological practice, but posttraumatic disorders, acute stress and social phobias are also common. ${ }^{35}$ Therefore, it is more appropriate to employ an instrument that is not limited to assessment of anxiety and depression, in order to avoid underestimation of psychosomatic involvement. We therefore chose to use the DLQI, which has been used previously with patients with atopic dermatitis to study the psychosocial associations of the disease. ${ }^{26,36}$

In the present study, disease severity was measured using the EASI. This instrument was developed by Hanifin et al. and they state that it has great precision for determination of the extent and gravity of $\mathrm{AD}$, in addition to being ideal for assessing the intensity of clinical presentation and the efficacy of treatment. ${ }^{17}$

The correlation between PSS-AD and EASI was low in this study $(<0.6)$, and the same was true of the correlation with the DLQI. This finding is similar to work reported by Salek et al. who investigated the effects of cyclosporine on $\mathrm{AD}$ and reported that there is really very little significant correlation between disease severity on one hand and psychosocial symptoms and quality of life on the other. ${ }^{37}$

\section{CONCLUSIONS}

In conclusion, the Brazilian Portuguese version of the PSS-AD proved to be a valid and reliable instrument for assessment of psychosomatic symptoms and can be used as a tool for clinical and therapeutic assessment of adult patients with atopic dermatitis.

\section{ACKNOWLEDGEMENTS}

The research team would like to thank Dr. Tetsuya Ando, the author of the original Japanese questionnaire, who authorized the adaptation and was always available to help whenever needed throughout the process. 


\section{REFERENCES}

1. Eichenfield LF, Hanifin JM, Luger TA, Stevens SR, Pride HB. Consensus conference on pediatric atopic dermatitis. J Am Acad Dermatol. 2003;49:1088-95.

2. Abramovits W. Atopic dermatitis. J Am Acad Dermatol. 2005;53:S86-93.

3. Ring J, Alomar A, Bieber T, Deleuran M, Fink-Wagner A, Gelmetti C et al. Guidelines for treatment of atopic eczema (atopic dermatitis) part I. J Eur Acad Dermatol Venereol. 2012;26:1045-60.

4. Katsarou A, Armenaka M. Atopic dermatitis in older patients: particular points. J Eur Acad Dermatol Venereol. 2011;25:12-8.

5. Illi S von Mutius E, Lau S, Nickel R, Grüber C, Niggemann B, et al. The natural course of atopic dermatitis from birth to age 7 years and the association with asthma. J Allergy Clin Immunol. 2004;113:925-31.

6. Bieber T. Atopic dermatitis. N Engl J Med. 2008;358:1483-94.

7. Arndt J, Smith N, Tausk F. Stress and atopic dermatitis. Curr Allergy Asthma Rep. 2008:8:312-7.

8. Harth W. Psychosomatic dermatology (psychodermatology). J Dtsch Dermatol Ges. $2008 ; 6: 67-76$.

9. Lammintausta K, Kalimo K, Raitala R, Forsten Y. Prognosis of atopic dermatitis. A prospective study in early adulthood. Int J Dermatol. 1991;30:563-8.

10. Ando T, Hashiro M, Noda K, Adachi J, Hosoya R, Kamide R, et al. Development and validation of the psychosomatic scale for atopic dermatitis in adults. J Dermatol. 2006;33:439-50.

11. Poot F, Sampogna F, Onnis L. Basic knowledge in psychodermatology. J Eur Acad Dermatol Venereol. 2007:21:227-34.

12. Hanifin JM, Rajka G. Diagnostic features of atopic dermatitis. Acta Derm Venereol (Stockh). 1980;92 (suppl 92):44 -7.

13. Herdman M, Fox-Rushby J, Badia X. A model of equivalence in the cultural adaptation of HRQoL instruments: the universalist approach. Qual Life Res. 1998;7:323-35.

14. Finlay AY. Quality of life in atopic dermatitis. J Am Acad Dermatol. 2001;45:S64-6.

15. Martins GA, Arruda L, Mugnaini ASB. Validation of life quality questionnaires for psoriasis patients. An Bras Dermatol. 2004;79:521-35.

16. Ferraz LB, Almeida FA, Vasconcellos MR, Faccina AS, Ciconelli RM, Ferraz MB. The impact of lupus erythematosus cutaneous on the Quality of life: the BrazilianPortuguese version of DLQI. Qual Life Res. 2006;15:565-70.

17. Hanifin JM, Thurston M, Omoto M, Cherill R, Tofte SJ, Graeber M. The eczema area and severity index (EASI): assessment of reliability in atopic dermatitis. EASI Evaluator Group. Exp Dermatol. 2001;10:11-8.

18. Dias GA, Pires GV, Valle SO, França AT, Papi JA, Dortas SD Jr, et al. Cross-cultural adaptation of the Brazilian-Portuguese version of the chronic urticaria quality-of-life questionnaire - CU-Q2oL. Allergy. 2011;66:1487-93.

19. Fayers P, Machin D. Quality of Life: The assessment, analysis and interpretation of patient-reported outcomes. 2nd ed. Chichester, London: John Wiley \& Sons Ltd; 2007.

20. Floyd FJ, Widaman KF. Factorial analysis in the development and refinement of clinical assessment instruments. Psychological Assessment. 1995;7:286-99.

21. Nunnaly JC, Bernstein IH. Psychometric Theory. 3rd ed. New York: Mc Graw- Hill; 1994.

22. Landis JR, Koch GG. An application of hierarchical kappa-type statistics in the assessment of majority agreement among multiple observers. Biometrics. 1977;33:363-74.

23. Grob JJ, Revuz J, Ortonne JP, Auquier P, Lorette G. Comparative study of the impact of chronic urticaria, psoriasis and atopic dermatitis on the quality of life. $\mathrm{Br} \mathrm{J}$ Dermatol. 2005;152:289-95.

24. Misery L, Finlay AY, Martin N, Boussetta S, Nguyen C, Myon E, et al. Atopic dermatitis: impact on the quality of life of patients and their partners. Dermatology. 2007;215:123-9.

25. Long CC, Funnell CM, Collard R, Finlay AY. What do members of the National Eczema Society really want? Clin Exp Dermatol. 1993;18:516-22.

26. Finlay AY, Khan GK. Dermatology Life Quality Index (DLQI)--a simple practical measure for routine clinical use. Clin Exp Dermatol. 1994;19:210-6.

27. Kiebert G, Sorensen SV, Revicki D, Fagan SC, Doyle JJ, Cohen J, et al. Atopic dermatitis is associated with a decrement in health-related quality of life. Int J Dermatol. 2002;41:151-8.

28. Coghi S, Bortoletto MC, Sampaio SA, Andrade Junior HF, Aoki V. Quality of life is severely compromised in adult patients with atopic dermatitis in Brazil, especially due to mental components. Clinics (Sao Paulo). 2007;62:235-42.

29. Deon KC, Santos DMdSSd, Bullinger M, Santos CBd. Preliminary psycometric assessment of the Brazilian version of the DISABKIDS ${ }^{\circledR}$ Atopic Dermatitis Module. Rev Saúde Pública. 2011;45:1072-8.
30. Amaral CS, March Mde F, Sant'Anna CC. Quality of life in children and teenagers with atopic dermatitis. An Bras Dermatol. 2012;87:717-23.

31. Alvarenga TMM, Caldeira AP. Quality of life in pediatric patients with atopic dermatitis. J Pediatr (Rio J.). 2009;85:415-20.

32. Linnet J, Jemec GB. An assessment of anxiety and dermatology life quality in patients with atopic dermatitis. Br J Dermatol. 1999;140:268-72.

33. Gupta MA, Gupta AK. Psychodermatology: an update. J Am Acad Dermatol. 1996;34:1030-46.

34. Gupta MA, Gupta AK, Schork NJ, Ellis CN. Depression modulates pruritus perception: a study of pruritus in psoriasis, atopic dermatitis, and chronic idiopathic urticaria. Psychosom Med. 1994:56:36-40.

35. Locala JA. Current concepts in psychodermatology. Curr Psychiatry Rep. 2009;11:211-8.

36. Lundberg L, Johannesson M, Silverdahl M, Hermansson C, Lindberg M. Health-related quality of life in patients with psoriasis and atopic dermatitis measured with SF36, DLQl and a subjective measure of disease activity. Acta Derm Venereol. 2000;80:430-4.

37. Salek MS, Finlay AY, Luscombe DK, Allen BR, Berth-Jones J, Camp RD, et al. Cyclosporin greatly improves the quality of life of adults with severe atopic dermatitis. A randomized, double-blind, placebo-controlled trial. $\mathrm{Br} J$ Dermatol. 1993;129:422-30.

\author{
MAILING ADDRESS: \\ Manuela Boleira \\ Rua Rodolpho Paulo Rocco, 255 \\ Cidade Universitária \\ 21941-913 - Ilha do Fundão - RJ \\ Brazil \\ E-mail:manuela.boleira@yahoo.com.br
}

How to cite this article: Boleira M, Lupi O, Pires GV, Dias G, Seba AJ, Guimaraes DBS. Translation and validation of Portuguese of a questionnaire for evaluation of psychosomatic symptoms in adults with atopic dermatitis. An Bras Dermatol. 2014;89(5):763-9. 